\title{
Fanconi anemia manifesting as a squamous cell carcinoma of the hard palate: a case report Giulio Gasparini*†, Gianluigi Longobardi ${ }^{\dagger}$, Roberto Boniello $^{\dagger}$, Alessandro Di Petrillo $^{\dagger}$ and Sandro Pelo ${ }^{\dagger}$
}

Address: U.O. Maxillofacial Surgery. Catholic University Medical School, Rome, Italy

Email: Giulio Gasparini* - giuliogasparini@yahoo.it; Gianluigi Longobardi - gianluigilongobardi@libero.it; Roberto Boniello - drboniello@yahoo.it; Alessandro Di Petrillo - alessandrodp9@hotmail.com; Sandro Pelo - sandro.pelo@rm.unicatt.it

* Corresponding author †Equal contributors

Published: 13 January 2006

Head \& Face Medicine 2006, 2:1 doi:10.1186/1746-160X-2-1
Received: 13 October 2005

Accepted: 13 January 2006

This article is available from: http://www.head-face-med.com/content/2/I/I

(c) 2006 Gasparini et al; licensee BioMed Central Ltd.

This is an Open Access article distributed under the terms of the Creative Commons Attribution License (http://creativecommons.org/licenses/by/2.0), which permits unrestricted use, distribution, and reproduction in any medium, provided the original work is properly cited.

\begin{abstract}
Fanconi Anemia is a rare autosomal recessive disorder characterized by various congenital malformations, progressive bone marrow failure at a very young age and of solid tumors development. The authors present a rare case of a squamous cell carcinoma of the hard palate in a Fanconi Anaemia patient. The atypical clinical manifestation rendered the diagnosis more difficult. This case, for age of appearance, sex and localization, is unique in international literature. We recommend a quarterly follow up of the oral-rhino-pharynx complex in FA patients and to consider as carcinomas, all oral lesions that last more than two weeks.
\end{abstract}

\section{Background}

Fanconi Anemia (FA) is a rare autosomal recessive syndrome (birth incidence of 1 per 350000), first described in 1927 as a progressive lethal anaemia associated with brown pigmentation of skin $[1,2]$. Subsequently, this term was extended to a syndrome that includes pancytopenia with hypoplastic bone marrow, skeletal, renal and ophtalmological malformations and chromosomal aberrations. The disease involves many organs including skin and genitourinary, musculoskeletal, cardiovascular and neurological systems. The clinical findings in FA patients are hyperpigmentation, small reproductive organs in males, kidney problems, thumbs and arm abnormalities, skeletal anomalies of hip, spine or ribs, low birth weight, short stature, growth retardation, defects of the tissue separating the heart chambers and mental retardation or learning disabilitym $[3,4]$. Most cases of FA manifest anaemia symptoms during childhood. However, the symptoms may not become apparent until adulthood $[5,6]$. FA patients are at risk for secondary malignancies, for example leukaemia, squamous cell carcinoma and hepatocellular carcinoma [7-9]. The risk of squamous cell carcinoma development is expecially high in the anogenital region as well as the head and neck region [10] Increased susceptibility of the oral cavity and anogenital region to local predisposing factors, including environmental toxins and viruses [5]. The authors report a new case of hard palate squamous cell carcinoma in a FA patient. The clinical history and localization of the tumour make this case unique.

\section{Case report}

The patient, a 27-year-old white male, was referred by a private oral surgeon to our hospital for evaluation of a hard palate lesion that had appeared six months before (Figure 1). The lesion had been diagnosed initialing as gingivitis by the private oral surgeon and treated with local topical medicines without any remission. 


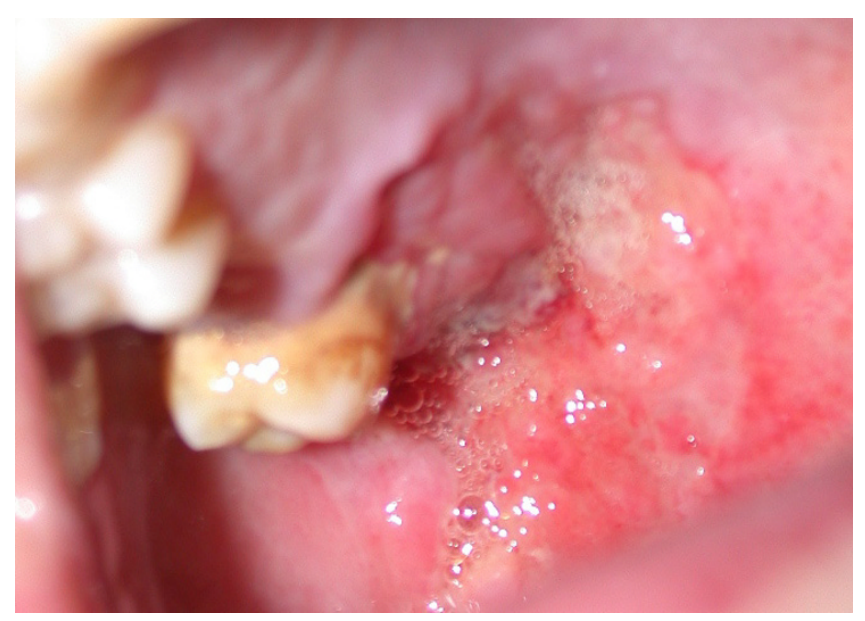

Figure I

Preoperative hard and soft palate lesion.

At the age of seven the patient was recovered for an orthopaedic trauma. He had been diagnosed with FA at the age of seven after that pancytopenia was noticed during routine blood examinations for orthodontic trauma. He had been treated with androgenic therapy and had not received a bone marrow transplant. The haematological test revealed an early stage of pancytopenia $(3,4 \times 109 / \mathrm{l}$, $\mathrm{Hb} 12,3 \mathrm{~g} / \mathrm{dl}$, and platelets $13 \times 10^{9} / \mathrm{l}$ ).

Oral examination revealed a relatively well-defined, nearly circular, concave ulcer measuring $3 \times 4 \mathrm{~cm}$, which extended from the hard palatal mucosa in the upper molar region to the adjacent soft palatal mucosa. The surface was erythematous and smooth, with some telangiectasias. Clinical examination showed no regional lymphadenopathy. CT and MR imaging showed a hard and soft tissue mass extending from molar region mucosa to the soft palate mucosa. The nasopharynx appeared normal (Figure 2). No significant cervical lymphadenopathy was seen on the images. An incisional biopsy performed under local anaesthesia revealed a well-differentiated squamous cell carcinoma (Figure 3 ).

The tumor was surgically removed with a right partial maxillectomy extendiney to homolateral soft mucosa and clear magins. Reconstruction was accomplished with a temporalis muscle flap. The patient has been followed up for 6 months without any evidence of recurrence or metastasis.

\section{Discussion}

Fanconi Anemia is a rare autosomal recessive disorder characterized by various congenital malformations, progressive bone marrow failure at a very young age and of solid tumors development. FA is defined by its cellular hypersensitivity to DNA cross-linking agent such as die- poxybutane (DEB) and mitomycin (MML). Presence of mutations of in one of the different FA genes, FA can be divided into eight complementary groups $(\mathrm{A}, \mathrm{B}, \mathrm{C}, \mathrm{D} 1$, D2, E, F, G), with each group having in common the cellular hypersensitivity to cross-linking agent. In the International Fanconi Anemia Registry (IFAR) complementation group A (65\%), C (15\%) and G (10\%) are the most common [11].

The severity is determined by specific complementation group and over all by the type of genetic mutation. Because of these phenotypic differences among complementation groups, FA is a heterogeneous disease. If impaired genetic factors cause an early appearance of the FA syndrome, the same factors may cause an early appearance of malignancies. Thus, there are two distinct groups of patients: (1) severe genetic disturbance with early FA symptoms and early malignancies; (2) mild disturbances with delayed FA symptoms and late malignancies [2]. Kaplan suggested that there are two defects determining the development of cancer in FA patients: defective chromosomal stability and immunodeficiency [12].

Patients that have endured bone marrow transplantation have a greater incidence of malignancies development. In these patients, there are four additional factors including pretransplant total body irradiation, cyclophosphamide treatment, chronic graft versus host disease, and prolonged immunosuppressive treatment after transplantation $[2,13,14]$.

The highest incidence of cancer development in FA patients is reported by Kuttler [11]. In this study he compared the incidence of Hard Neck Squamous Cell Carcinoma (HNSCC) in common population $(0.038 \%)$ and in FA patients (3\%). The first to describe a HNSCC in a FA patient were Esparza and Thompson [4]. Jansisyanont reported that the commonest localizations of squamous cell carcinoma in FA patients in descending order are: tongue, anogenital region, pharynx, larynx, oral mucosa, mandible and skin [13].

Lustig published a review of the international bibliography on the HNSCC in FA patients [2]. He presented 17 cases. In 13 patients the cancer localization was intra-oral. In 9 cases of these 13, the tongue was involved. According with this, in FA patients the tongue cancer incidence is $69 \%$, while in non FA patients the incidence varies by 10 to $16 \%$ [2].

Kuttler in 2003 referred that 19 of 754 patients in the International Fanconi Anaemia Registry (3\%) had HNSCC [11]. In the same year Bremer presented two cases of HNSCC [15], but in international literature no article has reported a hard palate localization of HNSCC. 


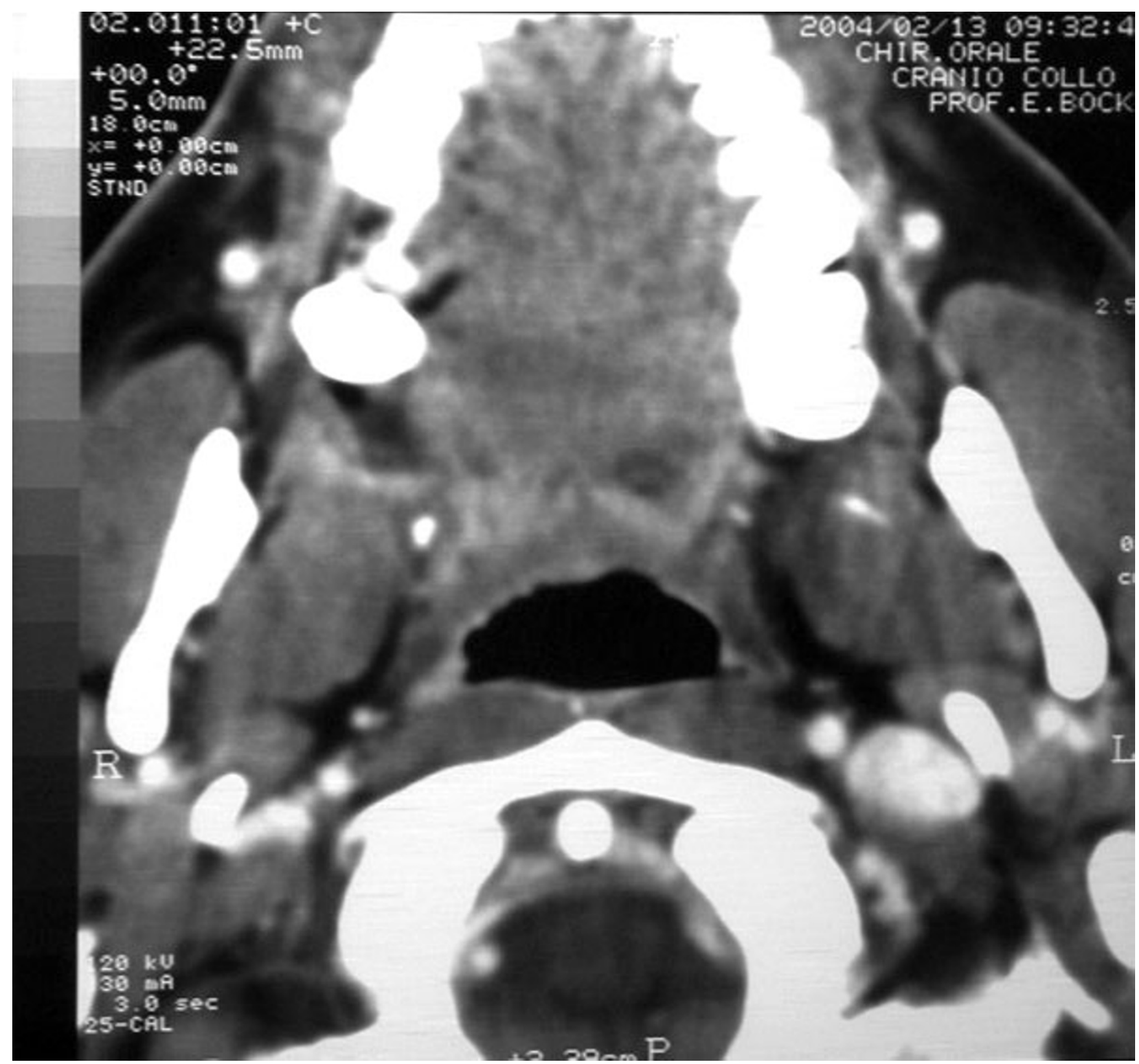

Figure 2

Preoperative CT image.

The male:female ratio of HNSCC in normal population is 2:1 while Reed asserted the reversed ratio in FA patients [16]. FA patients develop squamous cell carcinoma at significantly earlier age than the general population. Kenedy and Hart reported an average age of 27 years in FA patients [17] and the average time between age of FA diagnosis and cancer development is 10.5 years [2].

The treatment of malignancies in FA patients with HNSCC is similar to the general population with similar pathologies. The aim is the tumour resection oncologic radicality.
The main preoperative problem in patients with FA is the associated bone marrow failure, requiring preoperative haematologic consultations. The possibility of blood and platelet transfusion before surgery must be considered. We think that the first approach in FA patients is surgical resection of primary HNSCC with, if necessary, neck dissection and reconstruction. Generally, FA patients withstand surgical procedures very well. A further concern for the surgeon is the development of postoperative complications, including wound infections and haematoma. Although our patient did not develop postoperative com- 




Figure 3

Biopsy finding: Well-differentiated squamous cell carcinoma.

plications, FA patients can have serious problems in adjuvant therapy due to increased susceptibility to mutagenic stimuli $[2,11,13]$.

In FA patients, radiotherapy and chemotherapy follow different therapeutic principles. In FA patients the increased susceptibility to XRT and CTx can present problems to determine and to deliver a cancericidal dose without causing significant damage to normal tissue. Thus, in these patients standard doses for adjuvant therapy are generally reduced. Furthermore, the use of conventional protocols, which include cross-linking agents, can cause severe systemic complications, including irreversible aplastic anaemia and catastrophic organ damage $[15,18]$.
Because SCC in FA is difficult to treat once advanced, it is necessary to diagnose malignancies at early stage. We agree with the protocol proposed by Kutler [11]. He suggests a careful biannual screening of the oral cavity and oropharynx that should start between the ages of 15 and 20. However, in patients with FA with histrory of leucoplakia or recurrent oral lesions, head and neck examinations are recommended every six or eight weeks.

\section{Conclusion}

We report a unique localization of hard and soft squamous cell carcinoma in a FA patient. The atypical clinical manifestation rendered the diagnosis more difficult. We recommend a quarterly follow up of the oral-rhino-phar- 
ynx complex in FA patients and to consider as carcinomas, all oral lesions that last more than two weeks.

\section{Competing interests}

The author(s) declare that they have no competing interests.

\section{Authors' contributions}

GG drafted the manuscript. GL, RB and ADP carried out the literature search. All authors participated in the treatment of the patient. All authors read and approved the final manuscript.

\section{Acknowledgements}

We are very grateful to Prof. Vivek Shetty (UCLA School of Dentistry, Los Angeles, CA, USA) for his efforts and support in the final preparation of this manuscript for Head \& Face Medicine.

\section{References}

I. Fanconi G: Familiare infantile perniziosaartige Anämie (perniziöses Blutbild und Konstitution). Jahrbuch für Kinderheilkunde und physische Erziehung 1927, I 1 7:257-280.

2. Lustig JP, Lugassy G, Neder A, Sigler E: Head and neck carcinoma in Fanconi's anaemia-report of a case and review of the literature. Eur J Cancer B Oral Oncol 1995, 31:68-72.

3. Swift MR, Hirschhorn K: Fanconi's anemia. inherited susceptibility to chromosome breakage in various tissue. Ann Intern Med 1966, 65:496-503.

4. Esparza A, Thompson WK: Familial hypoplastic anemia with multiple congenital anomalies (Fanconi's syndrome) report of three cases. Cases presented are of two sisters and a female cousin with complete clinical and post mortem findings. RI Med J 1966, 49:103-II0.

5. Joenje $\mathrm{H}$, Matthew $\mathrm{C}$, Gluckman E: Fanconi anaemia research: current status and prospects. Eur J Cancer 1995, 3 I:268-272.

6. dos Santos CC, Gavish H, Buchwald M: Fanconi anemia revisited: old ideas and new advances. Stem Cells 1994, I 2: I 42-I53.

7. Linares M, Pastor E, Gomez A, Grau E: Hepatocellular carcinoma and squamous cell carcinoma in a patient with Fanconi's anemia. Ann Hematol 1991, 63:54-55.

8. LeBrun DP, Silver MM, Freedman MH, Phillips MJ: Fibrolamellar carcinoma of the liver in a patient with Fanconi anemia. Hum Pathol 1991, 22:396-398.

9. Moldvay J, Schaff Z, Lapis K: Hepatocellular carcinoma in Fanconi's anemia treated with androgen and corticosteroid. Zentralbl Pathol 1991, 137:167-170.

10. Oksuzoglu B, Yalcin S: Squamous cell carcinoma of the tongue in a patient with Fanconi's anemia: a case report and review of the literature. Ann Hematol 2002, $81: 294-298$.

II. Kutler DI, Auerbach AD, Satagopan J, Giampietro PF, Batish SD, Huvos AG, Goberdhan A, Shah JP, Singh B: High incidence of head and neck squamous cell carcinoma in patients with Fanconi anemia. Arch Otolaryngol Head Neck Surg 2003, I 29: 106-II 2.

12. Kaplan MJ, Sabio H, Wanebo HJ, Cantrell RW: Squamous cell carcinoma in the immunosuppressed patient: Fanconi's anemia. Laryngoscope 1985, 95:77|-775.

13. Jansisyanont P, Pazoki A, Ord RA: Squamous cell carcinoma of the tongue after bone marrow transplantation in a patient with Fanconi's anemia. J Oral Maxillofac Surg 2000, 58: I 454- I 457.

14. Socie G, Scieux C, Gluckman E, Soussi T, Clavel C, Saulnier P, Birembault P, Bosq J, Morinet F, Janin A: Squamous cell carcinomas after allogeneic bone marrow transplantation for aplastic anemia: further evidence of a multistep process. Transplantation 1998, 66:667-670.

15. Bremer M, Schindler D, Gross M, Dork T, Morlot S, Karstens JH: Fanconi's anemia and clinical radiosensitivity report on two adult patients with locally advanced solid tumors treated by radiotherapy. Strahlenther Onkol 2003, 179:748-753.
16. Reed K, Ravikumar TS, Gifford RR, Grage TB: The association of Fanconi's anemia and squamous cell carcinoma. Cancer 1983, 52:926-928.

17. Kennedy AW, Hart WR: Multiple squamous-cell carcinomas in Fanconi's anemia. Cancer 1982, 50:8II-8I4.

18. Alter BP: Radiosensitivity in Fanconi's anemia patients. Radiother Oncol 2002, 62:345-347.
Publish with Bio Med Central and every scientist can read your work free of charge

"BioMed Central will be the most significant development for disseminating the results of biomedical research in our lifetime. "

Sir Paul Nurse, Cancer Research UK

Your research papers will be:

- available free of charge to the entire biomedical community

- peer reviewed and published immediately upon acceptance

- cited in PubMed and archived on PubMed Central

- yours - you keep the copyright
BioMedcentral 